\title{
4
}

\section{A EMERGÊNCIA DO SERVIÇO SOCIAL NO ESPÍRITO SANTO}

\author{
Emergency Social Service in Espírito Santo \\ Raquel Mota Mascarenhas*
Gabriella de Souza Xavier**
}

\section{RESUMO}

O objetivo deste artigo é refletir sobre a relação entre "questão social" e Serviço Social no estado brasileiro do Espírito Santo entre 1940 e 1960. Para tal, em recusa a uma perspectiva endógena, destaca as particularidades da formação social estadual em que emerge o Serviço Social, observando sua institucionalização, principais demandas e sujeitos envolvidos neste processo.

\section{Palavras-Chave}

Espírito Santo. "Questão Social”. Serviço Social.

\section{ABSTRACT}

The objective article is socialize results bibliographical and documentary research relationship between "social question" and Social Service in state brasilian Espírito Santo between 1940 and 1960. In refusing an endogenous perspective, highlights particularities social formation state in which Social Work emerges, observing its institutionalization, main demands and subjects involved process.

\section{KEYWORDS}

Espírito Santo. "Social Question". Social Work.

Submetido em: 30/9/2018.

Aceito em: 12/12/2018.

\section{INTRODUÇÃO}

O presente artigo busca apreender a relação entre "questão social" e Serviço Social no estado brasileiro do Espírito Santo entre 1940 e $1960^{2}$.

\footnotetext{
* Assistente Social. Doutoranda no Programa de Pós-Graduação da Universidade Federal do Rio de Janeiro. Docente do curso de Serviço Social da Universidade Federal de Ouro Preto. R. Diogo de Vasconcelos, 122, Pilar, Ouro Preto (MG), Cep.: 354000-000. ORC ID: <https://orcid.org/0000-0003-2410-3429>. E-mail: $<$ rmmascarenhas.ufop@gmail.com>.

** Assistente Social. Mestre em Serviço Social. Servidora pública no cargo de Assistente Social da Universidade Federal do Rio de Janeiro (UFRJ). Av. Pedro Calmon, 550 - Cidade Universitária, Rio de Janeiro RJ, 21941-901. E-mail: < gabigabigaby@gmail.com>.

${ }^{1}$ Faz-se uso de aspas na grafia da "questão social" por: i) ratificar seu uso de modo divergente da sua gênese tradicional-conservadora (NETTO, 2009) e ii) não considera-la como categoria teórica no sentido marxiano e, sim, como conceito (IAMAMOTO, 2008; NETTO, 2009; SANTOS, 2008; SILVA, 2008).

${ }^{2}$ Tal recorte temporal considera o início da demanda de mão-de-obra especializada na execução das políticas sociais e o desvelar do regime autocrático da ditadura militar de 1964 no Brasil.
} 
Seu objetivo, portanto, é refletir acerca das particularidades do estado do Espírito Santo, uma vez que a maior parte das análises sociohistóricas da profissão é referenciada nas realidades de outras regiões do país, principalmente Rio de Janeiro e São Paulo. Além disso, a única bibliografia de maior fôlego que trata do tema é a de Floresta de Maria Soeiro Viza, uma dissertação de mestrado, apresentada em 1981, Reflexões sobre a evolução do Serviço Social: Espírito Santo (1950-1957). Essa obra se estrutura à luz de categorias analíticas que compreendiam o Serviço Social como evolução das antigas formas de ajuda. Logo, é de grande colaboração para aferição dos elementos constitutivos internos, mas carece de elementos constitutivos externos, que relacionem a profissão a totalidade da sociedade.

Portanto, visamos revisitar a história do Serviço Social no Espírito Santo pelo prisma da "questão social”, entendendo que "[...] a relação do Serviço Social com a questão social fundamento básico de sua existência - é mediatizada por um conjunto de processos sóciohistóricos e teórico-metodológicos constitutivos de seu processo de trabalho" (ASSOCIAÇÃO BRASILEIRA DE ENSINO E PESQUISA EM SERVIÇO SOCIAL, 1996).

Entretanto, o debate teórico acerca da "questão social" e sua incorporação pelo Serviço Social brasileiro é diverso - como Pierre Rosanvallon (1998) e Robert Castel (1998), vinculados ao pensamento durkheimiano (SANTOS, 2008), enquanto Cerqueira Filho (1982) e Octavio lanni (1991) ao pensamento marxiano ${ }^{3}$ (SILVA, 2008). Diante a isso, nos alinhamos à filiação teórica marxista e as contribuições de Marilda Villela lamamoto (2001; 2008) e de José Paulo Netto $(2007 ; 2009){ }^{4}$, que entendem a "questão social" como conjunto de desigualdades geradas pela exploração do trabalho no capitalismo, bem como as lutas sociais que delas advém. Como expõe lamamoto (2001):

[...] a questão social diz respeito ao conjunto das expressões das desigualdades sociais engendradas na sociedade capitalista madura, impensável sem a mediatização do Estado. Tem sua gênese no caráter coletivo da produção, contraposto a apropriação privada da própria atividade humana - o trabalho -, das condições necessárias à sua realização, assim como de seus frutos (IAMAMOTO, 2001, p. 16).

Isto é, a "questão social" se constitui no bojo do modo de produção capitalista e se expressa nas desigualdades sociais, políticas e culturais. Como ratifica Netto (2009):

[...] tomar a 'questão social' como problemática configuradora de uma totalidade processual específica é remetê-la concretamente à relação capital/trabalho [...] as sequelas da 'questão social' são recortadas como problemáticas particulares (o desemprego, $a$ fome, $a$ carência habitacional, o acidente de trabalho, $a$ falta de escolas, $a$ incapacidade física etc.) (NETTO, 2009, p. 32).

Essa compreensão permite expor a limitação do puro endogenismo pois entende que o Serviço Social, profissão institucionalizada no Brasil na década de 1930, emerge como “[...]

\footnotetext{
3 Destaca-se esses autores devido a influência que exercem no debate acerca da "questão social" no Serviço Social brasileiro (PASTORINI, 2004).

4 Embora existam diferenças entre os autores, ambos possuem como referência que a gênese da "questão social” se situa na lei geral de acumulação capitalista. Outras nuances podem ser observadas em Silva (2008), por exemplos nas abordagens de Vicente Faleiros, Maria Carmelita Yasbek e Potyara Pereira.
} 
expressão de necessidades sociais derivadas da prática histórica das classes sociais no ato de produzir e reproduzir os meios de vida e de trabalho de forma socialmente determinada [...]" (IAMAMOTO; CARVALHO, 2008, p. 76), ou seja, inserido na e fruto das relações sociais capitalista e, consequentemente, da divisão social, técnica e sexual do trabalho5.

Apesar de tal avanço, a produção teórica acerca da "questão social" e da emergência do Serviço Social no Brasil estagnou no nível da universalização, sendo o desafio realizar as mediações histórico-concretas que possibilitem particularizar a análise a partir do intercruzamento entre as variáveis históricas (NETTO, 2009; SANTOS, 2008). Avançar nesse sentido requer colocar o conceito marxista de formação social como central, entendendo que “[...] em Marx, a noção de 'formação social' [...] é sempre entendida no sentido dinâmico e não estático; como um processo, em suma, e não como a substância (por assim dizer) de uma época ou de uma fase histórica em si mesma imóvel e acabada" (SERENI, 2013, p. 304). Assim, é imperativo apreender a formação social capixaba, para elencar as particularidades da "questão social", indispensáveis a esse debate dos fundamentos do trabalho profissional.

Para isso, além da apresentação dessa introdução e considerações finais, esse artigo aborda o processo de institucionalização do Serviço Social capixaba em três dimensões: desenvolvimento retardatário e problemas sociais; protoformas e campos de trabalho; influência católica e direção social.

\section{DESENVOLVIMENTO RETARDATÁRIO E OS PROBLEMAS SOCIAIS}

A proposta desse estudo é revisitar a história do Serviço Social no Espírito Santo a partir do prisma da "questão social", o que requer conhecer a formação social do estado. Essa, tem como característica fundante o desenvolvimento econômico retardatário, que diz respeito a sua inserção periférica ${ }^{6}$ na economia do Brasil, visto seu histórico patamar de atraso7, em relação aos demais estados brasileiros, no que tange ao modelo de desenvolvimento capitalista urbano-industrial. Assim, os primeiros ensaios de industrialização se verificaram a partir de 1950 e a urbanização, que se dá nesse período, é fruto a atividade comercial.

\footnotetext{
${ }^{5} \mathrm{~A}$ divisão social do trabalho se dá pela necessidade de diferente produtos e ocorre em todos os modos de produção. A divisão técnica do trabalho, entretanto, é uma característica própria do modo de produção capitalista, correspondendo a uma forma de produção fragmentada e especializada. Por fim, "A divisão sexual do trabalho resulta de um sistema patriarcal capitalista que por meio da divisão hierárquica entre os sexos, confere às mulheres um baixo prestígio social e as submete aos trabalhos mais precarizados e desvalorizados" (CISNE, 2015, p. 117).

${ }^{6}$ Tal afirmação é possível a partir do intercruzamento das bibliografias que tratam sobre a "questão social" no Brasil (IAMAMOTO, CARVALHO, 2008; NETTO, 2007; SILVA, 2008) e aquelas que retratam a formação social capixaba (ABREU, 1993; ALMADA, 1984; BITENCOURT, 2006; COLBARI, 1997, 1998; ESPÍRITO SANTO SÉCULO XXI, 1987; GRAZZIOTTI, 2006; MATTEDI, 2009; PACHECO, 1998; SILVA, 1987, 1995, 2004; SIQUEIRA, 2001). Para maior aprofundamento acerca desse debate, ver Mascarenhas e Xavier (2009).

7 O patamar de atraso se constitui, dentre outros elementos, ainda durante o período colonial em que Portugal designou o território espírito-santense enquanto barreira verde, a fim de proteger o centro econômico dinamizador durante o apogeu do ciclo do ouro (ABREU, 1993). Aliado a isto, tem-se a postura conservadora da elite capixaba, que majoritariamente se manteve ao lado dos projetos políticos da burguesia cafeeira, mesmo quando a industrialização já se fazia dominante no cenário nacional (SILVA, 1995).
} 
Consequentemente, a inversão populacional no Espírito Santo - quando a população urbana ultrapassa a rural -, iniciada na década de 1950, se conclui apenas nos anos 1980. Ou seja, o aumento da população urbana, comparado ao conjunto da região sudeste, é pouco expressivo e demonstra as especificidades da base econômica do Espírito Santo, que permanece agrária até o início da industrialização pesada na década de 1970.

A formação social capixaba, portanto, diverge, em certa medida, da observada no eixo $\mathrm{RJ} / \mathrm{SP}$. Isto equivale a dizer que a "questão social" estava posta no estado, ainda que a industrialização e urbanização não fossem predominantes. O que nos leva a considerar que o desenvolvimento estadual, inclusive a própria intervenção do Estado nas expressões da "questão social”, se deu mediada pelas diretrizes dos governos nacionais.

Com relação à implantação de serviços sociais, o governo estadual lançou mão de sua utilidade, na medida em que se verificavam mudanças ocorridas na legislação nacional principalmente com relação ao Estado assumir os custos da reprodução da força de trabalho, ou seja, a legislação trabalhista e a assistência, cada vez mais racionalizada. No entanto, sabe-se que os serviços sociais contempla duplo movimento, de modo que aparecem como concessão do Estado ou dos capitalistas, mas são essencialmente vitórias dos sujeitos que têm, historicamente, o fruto de seu trabalho expropriado. Sendo assim, diante a bibliografia utilizada, aponta-se para pistas da existência de forças sociais capazes de reivindicar na arena política seus interesses, em contraponto a atuação corporativista e paternalista do Estado.

Nessa perspectiva, busca-se ir além das contribuições de Viza (1981) e a ênfase que concede as ações pioneiras e ou visionária dos agentes especializados para lidar com os problemas sociais. Pois, segundo sua pesquisa, a criação do Serviço Social no Espírito Santo decorreu das relações da inegável pioneira Geny Grijó, primeira assistente social capixaba, com a LBA e o governo estadual. Processo iniciado em 1944, com a transferência de Geny Grijó, então funcionária da Secretaria Estadual de Educação, para a LBA, após requisição da instituição. Essa, logrou destaque na execução de suas atividades e, após a participação no curso de Legionárias Visitadoras em São Paulo, obteve em 1946, juntamente com Alzira Turra, uma bolsa de estudos em Serviço Social, optando pela escola do Rio de Janeiro (VIZA, 1981).

Em seu retorno, Geny Grijó não se articulou com a própria instituição que lhe ofertou uma bolsa de estudos, a LBA. Isso porque considerava que a assistência social na instituição já estava organizada suficientemente, devido aos conhecimentos que havia trazido dos cursos que fizera anteriormente em São Paulo, em 1944, como ela elucida:

\footnotetext{
Verificando, entretanto, que a CE [Comissão Estadual da LBA] estava bem estruturada, desenvolvendo um programa de trabalho dentro de sua finalidade, a assistente social recém-chegada optou pela prestação de serviços ao segundo, porque o Estado nada possuía no plano social e ainda mais se servisse à LBA ficaria desenvolvendo sua atuação em um âmbito restrito, enquanto que um Serviço Social no Estado daria oportunidade a uma ação ampla, podendo atingir os mais variados setores (GRIJÓ, 1967, p. 06).
}

Assim, com seu retorno em 1949, com a recente extinção da Secretaria Estadual de Saúde e Assistência Social, Geny Grijó expõe ao diretor do Departamento Estadual de Saúde, Dr. Jaime dos Santos Neves, suas intenções. Esse, elucida que, desde que assumiu o 
Departamento, preocupa-se com o problema social, indissociável do problema médico, e que não o fizera por ausência de elemento especializado (VIZA, 1981). Sanado tal carência e com o aval do então governador do estado, Carlos Lindenberg, autorizou a criação da Agência de Serviço Social do Centro de Saúde de Vitória, em janeiro de 1950, sendo essa inaugurada em março de 1951, no governo de Jones dos Santos Neves (VIZA, 1981).

Acerca disso, observa-se que a autora concede grande significado ao encontro entre a assistente social e o diretor ${ }^{8}$ para o surgimento e expansão do Serviço Social no estado, entendo a profissão como consequência da evolução da caridade. Nesse viés, nas considerações finais de seu trabalho, Viza (1981, p.149) observa que "[...] a expansão do Serviço Social nos anos 50 deu-se mais por idealismo das pioneiras do que por uma conquista profissional [...]". Assim, considera que

\begin{abstract}
O Serviço Social consistiu-se na primeira forma de ajuda do Governo do Estado aberta a todas as populações marginalizadas e aparece neste contexto em que há uma grande preocupação por parte do Governo Estadual em ajudar a resolver os problemas sociais influenciados pelas consequências da situação sócioeconômica do Estado. O Governo pretendia ajudar a pobreza mas havia ausência de possibilidades reais em fazê-lo. $O$ aparecimento do Serviço Social nessa fase parece resolver este impasse, recebendo para isso todo o apoio governamental. Nesse momento histórico, a aparição de uma assistente social veio como uma resposta e uma resolução-salvadora para os problemas sociais decorrentes da crise do momento e das anteriores, saldo de outras épocas (grifo nosso) (VIZA, 1981, p. 67).
\end{abstract}

Assim, ainda que a autora escamotei de sua análise a centralidade das relações sociais, é explicita a relação existente entre a demanda por agente especializado, assistente social, e os problemas sociais, as expressões da "questão social". Isto é, no cenário estadual daquele momento, tinha-se expresso as mazelas do desenvolvimento capitalista, que passou a ser alvo de preocupação do Estado.

Nesse sentido, observando a obra de Viza (1981) é possível apreender quais foram as principais expressões da "questão social" colocadas como demanda inicial ao Serviço Social no estado. Estas podem ser relacionadas ao processo de industrizalização/urbanização que se intensificou a partir da década de 1950 - ainda que a industrialização pesada se dê apenas na década de 1970 e a inversão populacional nos anos 1980. Dessa maneira, apontamos que a pobreza urbana e suas implicações representaram as principais demandas à profissão neste momento, como as condições de habitação, a falta de saneamento básico nos bairros periféricos, a mendicância, as questões relativas à saúde pública e à infância. Além disso, a moralização e o controle ideológico das camadas populares, demonstrando as preocupações do empresariado e do Estado com relação à

\footnotetext{
${ }^{8}$ Não ignoramos a visível mudança analítica acerca do processo de surgimento do Serviço Social no Espírito Santo, perceptível no artigo publicado em 1990, no qual a autora considera outros elementos explicativos, indo além da ênfase nas ações pioneiras: “Neste clima de 'benesse' do aparato político do Estado, no seio do contexto 'balançado' da economia cafeeira sensível aos preços internacionais, a 'preocupação' com os 'empobrecidos' ex-ruricúlas colocavam a classe dominante política e civil aberta a proposta que vislumbrassem saídas para reverter o quadro incomodo que se desenhava emoldurando as maiores cidades" (VIZA, 1990, p. 96). Entretanto, para essa pesquisa, elegemos sua dissertação para análise, pois abrange mais dados históricos.
} 


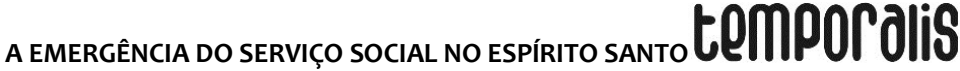

reprodução da força de trabalho - elementos indispensáveis no processo de desenvolvimento industrial.

\title{
PROTOFORMAS E CAMPOS DE TRABALHO
}

A análise da emergência do Serviço Social no Espírito Santo requer compreender o papel do Estado, na figura do governo estadual, que se redireciona para preservar a hegemonia burguesa e atender cada vez mais às regras da idade dos monopólios, assumindo, assim, responsabilidades antes não exercidas (NETTO, 2009). Esse processo se expressa em âmbito estadual em 1951, via Plano de Valorização Econômica do Estado (PVEE) do governo Jones dos Santos Neves, que expressa um debute da política desenvolvimentista em solo capixaba via intervencionismo estatal com vistas a industrialização (SILVA, 1995).

O que ratifica a emergência da profissão no bojo das relações sociais capitalistas, entendendo que a demanda de atuação junto aos setores dominados, não é por eles diretamente requerido, mas atende essencialmente a necessidade da manutenção da reprodução social capitalista (IAMAMOTO; CARVALHO, 2008). Entretanto, no discurso profissional prepondera a compreensão de que as ações profissionais atendiam as necessidades da população usuárias dos serviços. Como expõe Grijó (1967):

\begin{abstract}
Devemos afirmar, em sã consciência, que em 1951 o trabalho comunitário era uma constante nas atividades do Serviço Social e a prova foi o surgimento de vários serviços já mencionados. Enquanto as auxiliares sociais cuidavam dos casos isoladamente, a Chefe [a assistente social] permanecia atenta às necessidades comunitárias, [...] atendendo às verdadeiras aspirações e necessidades daquela comunidade [...] (GRIJÓ, 1967, p. 7).
\end{abstract}

Observa-se no discurso profissional, portanto, o entendimento da política social como solução dos problemas sociais, o que promove a convergência de ideias entre a assistente social, Geny Grijó, e o Estado, Dr. Jaime dos Santos Neves (VIZA, 1981). Nesse sentido, temse a vinculação dos primeiros campos de trabalho com a criação das grandes instituições assistenciais ${ }^{9}$ patrocinadas por associações patronais e pelo governo no Estado Novo - a exemplo, no Espírito Santo: Serviço Social da Indústria (SESI), Serviço Social do Comércio (SESC) e Legião Brasileira de Assistência $(\text { LBA })^{10}$.

O SESI, criado nacionalmente em 1946, instala uma unidade na capital espírito-santense e outra em Cachoeiro de Itapemirim, em 1951. A equipe inicial contava com Geny Grijó e três auxiliares sociais, posteriormente admitidas como assistentes sociais. A criação do SESC se deu em 1946, sendo fundado no Espírito Sano um ano depois e constituído pelo serviço médico, odontológico e de enfermagem. Isto é, só admite o Serviço Social posteriormente, em 1957. Por fim, em 1942, foi criada a LBA, em âmbito nacional e também estadual presidida pela primeira-dama, Alzira Herondina Donat Bley. Seguindo as diretrizes nacionais, a instituição promove preparo técnico, via cursos diversos, como o de Auxiliares

\footnotetext{
${ }^{9}$ lamamoto e Carvalho (2008, p. 269-270) afirmam que as grandes instituições assistenciais expressão a organização do empresariado e do governo Vargas frente à "questão social" no período da guerra fria, figurando como um verdadeiro "esforço de guerra" para manutenção da ordem social.

${ }^{10}$ Outras instituições que podem ser consideradas nesse bojo, mas que não figuraram como campo pioneiro do Serviço Social no Espírito Santo, foram o Serviço Nacional de Aprendizagem Industrial (SENAI) e a Fundação Leão XIII. Para maior aprofundamento acerca destas, ver lamamoto e Carvalho (2008).
} 


\section{temporalis}

Sociais e Familiares, em 1943 - ministrado por Mlle. Marsaud, diretora do Instituto Social do Rio de Janeiro, após a articulação da presidente nessa época, a primeira dama Alda Santos Neves - e dois cursos de Visitadoras Sociais, um para a capital e outro para o interior em 1945 (VIZA, 1981).

Portanto, a LBA no Espírito Santo, não se institui como campo de trabalho do Serviço Social, podendo ser considerada uma das protoformas da profissão no estado, pois,

O elemento humano e base organizacional que viabilizaram o surgimento do Serviço Social se constituirão a partir da mescla entre as antigas Obras Sociais que se diferenciavam criticamente da caridade tradicional - e os novos movimentos de apostolado social, especialmente aqueles destinados a intervir junto ao proletariado, ambos englobados dentro da estrutura do Movimento Laico, impulsionado e controlado pela hierarquia" (IAMAMOTO; CARVALHO, 2008, p. 167-168).

Além dessa protoforma, observando Grazziotti (2006), pode-se considerar, nas décadas de 1930 e 1940 no estado, a existência de obras sociais, tais como o Asilo Coração de Jesus, o Orfanato Santa Luiza, o Orfanato Christo Rei, o Asilo Cristo e Caridade, além de algumas escolas vinculadas à Igreja, porém destinadas à elite capixaba. Isso porque

Mais do que uma obrigação do governo à sociedade, a mentalidade da época vislumbrava o papel religioso incluso na caridade social e considerava sua obrigação cuidar desses desvalidos através de auxílios destinados a essas instituições filantrópicas. Assim, havia uma união entre o poder governamental, o poder religiosos e a sociedade, na prerrogativa de auxiliar os desvalidos através de ações caritativas que deveriam ter um objetivo próprio, seja no sentido de resguardar os valores dessa sociedade ou simplesmente por amor ao próximo (GRAZZIOTTI, 2006, p. 156).

Ademais, Viza (1981) demonstra a contribuição das Irmãs de Caridade de São Vicente de Paula para o crescente processo de racionalização da assistência. Essas, advindas da França no início do século XX, criaram a Associação das Damas de Caridade, em 1904, formada por senhoras da sociedade capixaba.

Destarte, reafirma-se que a LBA foi a instituição que mais serviu de base para a emergência posterior do Serviço Social, devido ao maior processo de racionalização da assistência, pois, como pode se observa-se em Viza (1981), a LBA foi

[...] um divisor de águas entre a assistência tradicional, paternalista, não sistematizada tecnicamente, sem preocupar-se com a pessoa do assistido para uma nova proposta que contém característica das formas anteriores, mas que contém inovações. Esta instituição além de conter dados significativos do passado no que tange ao ato de ajudar os mais carentes preparou certas précondições para a implantação do Serviço Social conforme se pode observar na dinâmica de sua organização e prática social que mais se assemelha à proposta do Serviço Social (VIZA, 1981, p. 54).

Este esforço de identificar as protoformas é central no estudo da gênese do Serviço Social, pois, ainda que as ações e conteúdos fossem essencialmente paternalistas e limitados - ao contrário do que aponta Viza (1981) -, constituíram a base organizacional, material e humana para emergência da profissão e das primeiras escolas. 
No que tange aos campos de trabalho do Serviço Social, pode-se identificar em Visa (1981) dois grupos. O primeiro tange aqueles que foram desenvolvidos por auxiliares sociais e, posteriormente, alunas da primeira escola de Serviço Social.

Tabela 1: Campos Pioneiros iniciados com Auxiliares Sociais

\begin{tabular}{|l|c|}
\hline \multicolumn{1}{|c|}{ CAMPOS } & $\begin{array}{c}\text { ANO DE } \\
\text { CRIAÇÃO }\end{array}$ \\
\hline LBA & 1942 \\
\hline Sanatório Getúlio Vargas & 1950 \\
\hline Santa Casa de Misericórdia de Vitória & 1952 \\
\hline Centro Social Ilha do Príncipe & 1953 \\
\hline Clínica de Câncer da Santa Casa de Misericórdia de Vitória & 1953 \\
\hline Administração do Porto de Vitória & 1953 \\
\hline Obra Social Santa Luiza & 1953 \\
\hline Juizado de Menores & 1953 \\
\hline Lavanderia da Fonte Grande & 1954 \\
\hline
\end{tabular}

Fonte: organização das autoras

Portanto, apesar da denominação "Serviço Social", em todos esses campos pioneiros, eram as auxiliares sociais que desenvolviam as atividades, algumas sob a supervisão da assistente social Geny Grijó. Porém, ao fim do primeiro curso de auxiliares sociais, elas sugeriram a criação de um curso superior em Serviço Social (VIZA, 1981).

Cumpre ratificar que a demanda pela criação destas Agências de Serviço Social partiram do governo estadual - com exceção do Porto de Vitória e da Clínica de Câncer da Santa Casa de Misericórdia de Vitória. Nesse sentido, é possível perceber que o Estado, além de ter sido o lócus de surgimento do Serviço Social, foi também o grande responsável pela legitimação e expansão da profissão. Em suma, no Espírito Santo viu-se a participação mais intensa do Estado nesse aspecto, seja na figura do Judiciário, seja do Executivo estadual.

Os demais campos pioneiros listados por Viza (1981), surgidos ainda na década de 1950, foram abertos já por assistentes sociais formadas no Espírito Santo.

Tabela 1: Campos Pioneiros iniciados com Assistentes Sociais

\begin{tabular}{|l|l|}
\hline \multicolumn{1}{|c|}{ CAMPOS } & $\begin{array}{c}\text { ANO DE } \\
\text { CRIAÇÃO }\end{array}$ \\
\hline Centro de Saúde de Vitória11 & 1950 \\
\hline SESI & 1951 \\
\hline Albergue Noturno & 1951 \\
\hline IBES & 1952 \\
\hline Colégio Americano Batista & 1954 \\
\hline Hospital Infantil Nossa Senhora da Glória & 1956 \\
\hline Pesquisa Social em Favelas de Vitória & 1957 \\
\hline Segundo Distrito Sanitário de Cachoeiro de Itapemirim & 1957 \\
\hline SESC & 1957 \\
\hline
\end{tabular}

Fonte: organização das autoras

Portanto, a partir deste panorama sobre os primeiros campos de trabalho no Espírito Santo, pode-se aferir o crescente quantitativo e diversificação da demandas direcionado ao

\footnotetext{
${ }^{11}$ Primeira instituição a inserir assistente social no quadro de funcionários.
} 
Serviço Social. De forma que, em 1960, se dá criação da Secretaria de Estado de Bem-Estar Social, que incorporou o trabalho que antes realizado pela Agência de Serviço Social do Centro de Saúde de Vitória (VIZA, 1981).

Acerca disso, tem-se que a emergência do Serviço Social está vinculado a emergência das políticas sociais no capitalismo monopolista, via a reorganização do Estado, que empreende respostas sistemáticas as expressões da "questão social" via políticas sociais (NETTO, 2009). Pode-se afirmar, nesse sentido, que a formação de agentes especializados para intervirem nas expressões da "questão social" foi uma demanda colocada pelo Estado, desde 1950. Nesse ano, após a criação da Agência de Serviço Social do Centro de Saúde de Vitória, sob o financiamento do Departamento Estadual de Saúde, Geny Grijó organiza a capacitação de trinta e uma auxiliares sociais, durante oito meses (VIZA, 1981).

Posteriormente, o Departamento Estadual de Saúde, na figura de seu diretor Dr. Jaime dos Santos Neves, articulou a criação do curso com Mlle. Marsaud, diretora do Instituto Social do Rio de Janeiro, mediada pela assistente social Geny Grijó ${ }^{12}$. Tal articulação culmina, em 1952, no convênio entre o governo estadual e a Associação das Escolas de Educação Familiar (AEFS), mantenedora do Instituto Social do Rio de Janeiro. Funda-se nesse ano, portanto, a Escola de Serviço Social capixaba, cuja primeira diretora foi a assistente social Stella Penna Botto, enquanto Geny Grijó ficou responsável pela supervisão de estágio. Para a inserção de estudantes foi previsto um sistema de bolsas (subsidiadas pela LBA, autarquias, municípios, etc.) e reserva de vagas para representantes do interior do estado ${ }^{13}$, no entanto nenhum município enviou candidatas (VIZA, 1981).

Desta forma, o curso foi iniciado com trinta e cinco alunas, e, após três anos de curso, a formação de treze profissionais, ou seja, em 1954, têm-se a primeira turma de assistentes sociais formadas no Espírito Santo. E, apesar da crescente demanda por assistentes sociais no estado, esta escola só formou uma turma ${ }^{14}$. O próximo curso, porém de auxiliares sociais, realizado em 1957, foi a última iniciativa do tipo avulsa, pois a regulamentação do ensino de Serviço Social (Decreto $n^{\circ} 35.311$, de 8 de abril de 1954), proibiu a abertura de cursos que não tivessem previsão de continuidade. Apenas, em 1958, é que ocorreu a reestruturação do curso superior em Serviço Social, não mais vinculado ao Departamento Estadual de Saúde, de modo que ficou a cargo da Igreja Católica, na figura da Arquidiocese de Vitória. A direção da escola ficou sob a responsabilidade das Freiras da Ordem Jesus Crucificado, sendo ainda o curso promovido pelo Instituto Social de Vitória, semelhante ao que ocorreu em algumas cidades brasileiras, como no Rio de Janeiro (VIZA, 1981).

\footnotetext{
${ }^{12}$ Colaboradores para criação da Escola de Serviço Social no Espírito Santo: presidente da Associação Brasileira de Ensino em Serviço Social (ABESS), Odila Ferreira; governador estadual, Jones dos Santos Neves; presidente da Comissão Estadual da LBA, Alda Santos Neves; médico da Santa Casa de Misericórdia de Vitória, Dr. Afonso Bianco; juiz da Vara de Menores da Comarca da Capital, José Vieira Coelho (VIZA, 1981).

${ }^{13} \mathrm{O}$ fato dos municípios não ter se interessado por agentes especializados para a intervenção social, pode sinalizar que, no interior, a repressão e filantropia ainda bastavam para o enfrentamento do problema social. 14 Não foi possível aferir o motivo da descontinuidade do curso de serviço social e opção pela formação de auxiliares sociais. Apesar de ser perceptível que a demanda por profissionais de Serviço Social crescia vertiginosamente, a autora justifica apenas que "[...] formar nova equipe de assistentes sociais é tarefa que, por razões diversas, não é oportuno. Necessário é, pois, organizar um curso de Auxiliares cujos elementos devidamente capacitados poderão atuar sobre a direção de assistente social diplomada" (VIZA, 1981, p. 102).
} 


\section{INFLUÊNCIA CATÓLICA E DIREÇÃO SOCIAL}

O último elemento de onde partimos nossa análise diz respeito ao papel da lgreja Católica na gênese e expansão do Serviço Social no Espírito Santo. Nos estados de São Paulo e Rio de Janeiro, sabe-se que este elemento foi basilar para o desenvolvimento das protoformas do que viria a se tornar a profissão de Serviço Social, na medida em que as práticas racionalizadas de assistência e controle da classe operária nasceram estreitamente ligadas ao movimento de apostolado social da Igreja (IAMAMOTO; CARVALHO, 2008).

No Brasil, desde a República Velha, a Igreja Católica resiste com êxito à iniciativa de laicização do Estado, em grande medida, por colaborar no processo de controle ideológico e social. Em particular, a partir da década de 1930, tem-se um verdadeiro partido da Igreja, com natureza autoritária, elitista, corporativista e hierárquica; e íntima vinculação com a Ação Integralista Brasileira (AIB), cuja filiação remete-nos ao fascismo europeu (IAMAMOTO; CARVALHO, 2008).

Diante à isso, a exemplo da emergência do Serviço Social no Rio de Janeiro e São Paulo, teria o laicato católico interferido na gênese e desenvolvimento do Serviço Social no Espírito Santo? Apesar de não dispormos de bibliografias específicas, identificamos algumas pistas que apontam para a reatualização da ideologia integralista, tanto durante o Estado Novo quanto no posterior e curto período de redemocratização.

Na cena política, tem-se o interventor federal capixaba, João Purano Bley (1930-1943), que seguia à risca as diretrizes federais de Vargas - que se vinculava ao fascismo europeu, através de sua articulação com a AIB -; e o governador estadual eleito, Jones dos Santos Neves (1951-1955), vinculado ao Partido Social Democrático (PSD), ligado à vertente integralista da ideologia nacionalista, e que também havia sido interventor federal (19431945). Outro elemento advém da imigração europeia, dado que os italianos e alemães eram afeitos a política corporativista, conforme seus países de origem. O que permite a instituição de lideranças católicas, como o Padre Ponciano dos Santos Stenzel, na constituição do Partido da Representação Popular (PRP), em 1945. Ademais, nacionalmente os votos católicos eram aglutinados através da Liga Eleitoral Católica (LEC), sendo que, no Espírito Santo, os membros da LEC passaram a compor, em 1946, a diretoria do Partido Democrata Cristão (PDC) - que objetivou sugerir o antigo interventor, João Purano Bley, ao pleito eleitoral do estado. Por fim, a trilogia integralista Deus, Pátria e Família encontrou terreno fértil no Espírito Santo, sendo amplamente disseminado, sobretudo pelos imigrantes (SILVA, 1995) 15.

A relação entre religião e Estado no Espírito Santo, também incorpora a religião protestante, chegando a incomodar os setores católicos. Como, por exemplo, após o Estado Novo, quando forças políticas advindas dos setores protestantes se organizaram no bojo do Partido Republicano Democrático (PRD) - fundado por Dr. Alberto Stange Júnior, presidente da Convenção Batista Capixaba e diretor do Colégio Americano Batista de Vitória (SILVA, 1995).

\footnotetext{
15 É verdade que o PRP e o PDC não eram partidos majoritários do sistema político capixaba, porém sua força estava na possibilidade de pender o fiel da balança do poder para lados distintos (SILVA, 1995).
} 


\section{tempordlis}

Todos esses elementos nos permite apontar para o tensionamentos entre católicos e protestantes presentes na gênese do Serviço Social no estado. Uma vez que, entre 1951, fim do primeiro curso de auxiliares sociais promovido pelo Centro de Saúde de Vitória, e 1952, ano de início das atividades da Escola de Serviço Social da mesma instituição, existiu a criação da Escola Técnica do Colégio Americano Batista de Vitória ${ }^{16}$, em 1951.

Para Viza (1981) a escola batista não alcança relevância, devido à apenas uma assistente social ter exercido a profissão, no próprio Colégio Americano Batista, logo, entende que esse não contribuiu para a expansão dos campos pioneiros. Além disso, a autora relata que a pioneira Geny Grijó foi convidada pela direção do Colégio a compor o quadro de professores da Escola, mas por razões éticas a autora não avança no sentido de compreender o porquê da recusa do convite - entretanto, isto nos leva a traçar algumas considerações. É tão somente pelo movimento do real apreendido neste trabalho que sinalizamos a necessidade de articular este fato às lutas ideológicas que passaram a ser travadas no seio da sociedade pelo movimento laico da Igreja Católica, na busca de garantir suas prerrogativas. Nessa perspectiva, uma vez identificada a demanda das auxiliares sociais pelo aprofundamento técnico, sugerindo a Geny Grijó a criação de um curso superior em Serviço Social, em 1951, por que razão a iniciativa do Colégio Americano Batista não foi reconhecida pela pioneira - senão pelas divergências ideológicas existentes? É preciso reconhecer, entretanto, que nas análises de Viza (1981) não existe nenhuma referência quanto à vinculação de Geny Grijó aos movimentos de apostolado social da Igreja Católica. Contudo, as evidências nos levam a considerar a existência dessa ligação, mesmo que indiretamente.

O primeiro elemento que a isso nos remete está no fato de que a pioneira realizou seus estudos numa escola historicamente vinculada à Igreja Católica, trazendo, pois, de lá toda bagagem ideológica. Segundo lamamoto e Carvalho (2008), à época, a Escola de Serviço Social do Rio de Janeiro era vinculada ao Instituto de Educação Social e Familiar, cuja mantenedora era a Associação de Educação Familiar e Social (AEFS), originada no seio da Ação Católica. Dessa forma, é possível afirmar que as ações do apostolado laico da Igreja interferiram, assim como em São Paulo e no Rio de Janeiro, no desenvolvimento do Serviço Social no Espírito Santo, de forma que também foi possível identificar um tensionamento político e ideológico entre as forças religiosas ${ }^{17}$ - pendendo para a manutenção da influência social do pensamento católico.

É possível afirmar a existência do movimento de reação católica no Espírito Santo, pois, além dos elementos demonstrado, este se expressa no primeiro curso de formação de auxiliares sociais, em que se exigia das candidatas (pois só se aceitavam elementos femininos) qualidades morais do apostolado social.

A execução das tarefas das alunas exigia ao lado dos conhecimentos teóricopráticos 'qualidades morais, algum espírito de sacrifício bem próximo a um apostolado'.

16

17 Pacheco (1998), ao descrever a vida cotidiana da capital, afirma que, estando Purano Bley no estado em 1930, setores da elite capixabas usavam de estratégias - como bailes em clubes - para convencê-lo a convergir ao seu lado no jogo político; e sinaliza que, nestes eventos, alguns bispos da Igreja Católica abordavam as famílias da elite capixaba para que não matriculassem seus filhos no Colégio Americano Batista de Vitória. 
Observa-se nessas exigências a presença do idealismo cristão no ato de ajudar, não só nas qualidades de quem ajuda como na expressão objetiva deste ato. Sabese que as origens do Serviço Social no Brasil, deve-se a idealistas cristãos que tomaram a si a tarefa de trazer esta nova forma de ajuda aos necessitados. $E$ todo o trabalho com o social no Espírito Santo, fora trazido por esses idealistas, ora por pessoas com 'qualidades especiais' que saíram para buscar conhecimento nos grandes centros trazendo consigo a influência cristã e europeia, configurada no modelo franco-belga (VIZA, 1981, p. 81).

Além desse, outro elemento que ratifica a influência da doutrina social católica, pode ser observado nos programas das disciplinas do curso de Serviço Social do Centro de Saúde de Vitória, que ratificam o pensamento franco-belga, tanto dos cursos de auxiliares sociais, em 1951 e 1957, quanto do curso de Serviço Social, em 1952, como o estudo das Encíclicas Papais (Rerum Novarum ${ }^{18}$ e Casti Connubi) (VIZA, 1981). Por fim, a íntima vinculação do Serviço Social capixaba com a Igreja Católica é corroborado, em 1958, quando a Arquidiocese de Vitória assumiu a manutenção da Escola de Serviço Social.

Tendo visto a preponderância da direção social católica, cabe destacar que, no que tange aos fundamentos teóricos-metodológicos, o Serviço Social no Espírito Santo emerge sob a influência franco-belga e, também, norte-americana. Isso, devido ao fato de que se deu na década de 1950, ou seja, momento em que o Serviço Social no Brasil já havia assimilado ambas as influências (IAMAMOTO; CARVALHO, 2008). Isso pôde ser observado na Agência de Serviço Social do Centro de Saúde de Vitória, onde se desenvolvia o Serviço Social de Casos, que consistia numa técnica norte-americana desenvolvida por Mary Richmond e tinha por finalidade o ajustamento do indivíduo ao meio social (VIZA, 1981).

É importante destacar que estes elementos foram materializados no primeiro Código de Ética Profissional, de 1947, cuja orientação exprimia visivelmente a vinculação da prática profissional aos princípios da caridade cristã (ABAS, 2009). Essa mesma perspectiva é observada no direcionamento dado à profissão no Espírito Santo, na medida em que se afirmava que havia um "[...] esforço do técnico em mobilizar a vontade e a inteligência do assistido para encontrar os meios necessários à superação de sua situação e ajustar-se à sociedade" (VIZA, 1981, p. 70).

Visa (1981) expõe que, para Geny Grijó, a finalidade do Serviço Social era promover o ajustamento, porém o próprio cliente era o responsável por remover as causas de seu desajustamento social, para que voltasse à vida normal. Dessa forma, a autora explicita que

O objeto material do Serviço Social era a pessoa humana desajustada. E sua finalidade 'era o ajustamento por meio da orientação dada ao assistido', tornando auto-suficiente e 'adaptado ao meio social, às suas necessidades' e, para isto, 'buscava as causas do desajuste, agindo sobre elas para eliminá-las ou diminuí-las' (VIZA, 1981, p. 72).

18 No programa do primeiro curso de auxiliares sociais, de 1950, consta “[...] comentários sobre a Encíclica Rerum Novarum [...]” (VIZA, 1981, p. 80) - escrito pelo Papa Leão XIII em 1981, norteia as ações do apostolado católico diante o conflito entre classes, nomeado de questão social. Nesse, o Papa contrapõe-se a solução socialista, por ser a propriedade privada uma lei divina; ratifica o dever do Estado de impedir greves e zelar pelos operários e familiares; e destaca a função da Igreja para solucionar a questão social (PAPA LEÃO XIII, 2009). 
Dessa maneira, o problema social - "questão social” - é reconhecido pelo Estado, que requisita o agente especializado - assistente social - para intervenção disciplinadora das classes subalternas no território espírito-santense.

\section{ALGUMAS CONSIDERAÇÕES}

Tendo em vista a proposta de revisitar a história do Serviço Social no Espírito Santo pelo prisma da "questão social", entendemos que observar a formação social capixaba tornou possível contribuir para a análise da profissão para além da perspectiva endógena.

Dessa forma, é possível afirmar que a emergência do Serviço Social encontrou solo fértil e estava intimamente sintonizada, ou melhor, foi diretamente funcional ao redimensionamento da economia e das estruturas do Estado no Espírito Santo. Tal processo é fecundo de peculiaridades, tendo em vista que o início da industrialização e urbanização do território se inicia na década de 1950 e se consolida na década de 1980. Isto é, a gênese do Serviço Social no Espírito Santo não se deu por motivações puramente idealistas e visionárias, pois estavam umbilicalmente relacionadas ao amadurecimento da sociabilidade capitalista no estado. Entretanto, o desenvolvimento tardio e autocrático capixaba evidencia que as iniciais expressões da "questão social" eram vistas como um problema a ser contido desde seu início, através de formas de enfrentamento, à exemplo do direcionamento do governo nacional.

Enquanto elementos particulares dessa institucionalização podemos descartar a LBA como uma protoforma do Serviço Social; as contribuições e tensionamentos dos setores católicos e evangélicos na criação dos curso profissionais; a influência concomitante do pensamento franco-belga e norte-americano; o maior destaque do Estado na criação dos campos pioneiros.

Por fim, a divulgação dos apontamento dessa pesquisa não pretende findar o estudo da historicidade do Serviço Social no Espírito Santo. Ao contrário, trata-se de uma colaboração que busca dar visibilidade à necessidade de se analisar e sistematizar esse campo de pesquisa que está aberto e carece de muito avanço.

\section{REFERÊNCIAS}

ASSOCIAÇÃO BRASILEIRA DE ENSINO E PESQUISA EM SERVIÇO SOCIAL. Diretrizes gerais para o curso de Serviço Social: com base no currículo mínimo aprovado em assembleia geral extraordinária de 8 de novembro de 1996. Rio de Janeiro: ABEPSS, 1996.

ABREU, Carol. O desejo da conquista. In: VASCONCELOS, J. G. (Org.). Vitória: Trajetórias de uma cidade. Vitória: IHGES, 1993.

ALMADA, Vilma Paraíso Ferreira de. Escravismo e transição: o Espírito Santo (1850-1888). Rio de Janeiro: Graal, 1984.

BITENCOURT, Gabriel Augusto de Mello. História geral e econômica do Espírito Santo: do engenho colonial ao complexo fabril-portuário. Vitória: Multiplicidades, 2006. 
CARDOSO, Lavínia Coutinho. Revolta Negra na Freguesia de São José do Queimado: escravidão, resistência e liberdade no século XIX na província do Espírito Santo (1845 - 1850). 2008.

Dissertação (Mestrado em História Social das Relações Políticas) - Universidade Federal do Espírito Santo, Vitória. 2008.

CASTEL, Robert. As metamorfoses da "questão social": uma crônica do salário. 6. ed. Trad. Iraci Poleti. Petrópolis: Vozes, 1998.

CERQUEIRA FILHO, Gilásio. A questão social no Brasil: crítica do discurso político. Rio de Janeiro: Civilização Brasileira, 1982.

CISNE, Mirla. Divisão sexual do trabalho na ordem "sociometabólica" do capital - uma análise necessária para a emancipação das mulheres. In: CISNE, Mirla. Gênero, divisão sexual do trabalho e serviço social. 2. ed. São Paulo: Outras Expessões, 2015.

COLBARI, Antônia. Família e trabalho na cultura dos imigrantes italianos. In: CASTIGLIONI, Aurélia H. (Org.). Imigração Italiana no Espírito Santo: uma aventura colonizadora. Vitória: UFES, 1998.

COLBARI, Antônia. Imigrantes Italianos no Espírito Santo. Revista Brasileira de História, São Paulo, v. 17, n. 34, 1997.

REDE GAZETA; UFES; GERES; BANDES; COPLAN. Espírito Santo Século XXI: Estratificação de classes e atomização social. Vitória: Rede Gazeta/ UFES/ GERES/ BANDES/ COPLAN, 1987.

GRAZZIOTTI, Marinete Simões. Dever do Estado e direito do cidadão: as políticas públicas no governo varguista no Espírito Santo (1930-1945). Dissertação (Mestrado em História) Universidade Federal do Espírito Santo, Vitória. 2006.

GRIJÓ, Geny. A Assistência Social no Espírito Santo. Vitória: LBA, 1967.

IAMAMOTO, Marilda Vilela. A “questão social” no capitalismo. Temporalis, Porto Alegre, ano 2, n. 3. 2001.

IAMAMOTO, Marilda Vilela; CARVALHO, Raul de. Relações sociais e serviço social no Brasil: esboço de uma interpretação histórico-metodológica. 21. ed. São Paulo: Cortez, 2008.

IANNI, Otavio. A idéia de Brasil moderno. São Paulo: Brasiliense, 1991.

MATTEDI, José Carlos. Um século da primeira greve operária no Espírito Santo. Revista A’angaba, Vitória, ano I, n. 5, 2009.

NETTO, José Paulo. Capitalismo Monopolista e Serviço Social. 7. ed. São Paulo: Cortez, 2009. NETTO, José Paulo. Ditadura e serviço social: uma análise do serviço social no Brasil pós-64. 10. ed. São Paulo: Cortez, 2007.

PACHECO, Renato Jose Costa. Os dias antigos. Vitoria: EDUFES, 1998.

PAPA LEÃO XIII. Carta encíclica rerum novarum sobre a condição dos operários, 1981. A Santa Sé [portal de notícias do Catolicismo no Vaticano], Libreria Editrice Vaticana, 1981. Disponível em: <http://www.vatican.va/holy_father/leo_xiii/encyclicals/documents/hf_l-xiii_enc_15051891_rerumnovarum_po.html $>$. Acesso em: 01 nov. 2009. 
PASTORINI, Alejandra. A categoria “questão social” em debate. São Paulo: Cortez, 2004. (Coleção Questões de Nossa Época).

QUIROGA, Consuelo. Invasão Positivista no Marxismo: manifestações no ensino da metodologia no Serviço Social. São Paulo: Cortez, 1991.

ROSANVALLON, Pierre. A nova questão social: repensando o Estado-providência. Brasília: Instituto Teotônio Vilela, 1998.

SANTOS, Josiane Soares. Particularidades da "questão social" no capitalismo brasileiro. 2008. Dissertação (Mestrado em Serviço Social) - Universidade Federal do Rio de Janeiro, Rio de Janeiro, 2008.

SERENI, Emílio. De Marx a Lênin: a categoria de "formação económico-social”. Meridiano, Buenos Aires, n. 2, 2013.

SILVA, Ivone Maria Ferreira da. Questão Social e Serviço Social no Brasil: fundamentos sociohistóricos. Cuiabá: EdUFMT, 2008.

SILVA, Marta Zorzal e. A Vale do Rio Doce na estratégia do desenvolvimentismo brasileiro. Vitória: EDUFES, 2004.

SILVA, Marta Zorzal e. Espírito Santo: Estado, interesse e poder. Vitória: Fundação Ceciliano Abel de Almeida/ UFES/ Secretaria de Produção/ Difusão Cultural, 1995.

SILVA, Marta Zorzal e. Interesses em jogo. Revista IJSN, Vitória, ano VI, n. 2, jul./set. 1987.

SIQUEIRA, Maria da Penha Smarzaro. Industrialização e empobrecimento urbano: o caso da Grande Vitória, 1950-1980. Vitória: EDUFES, 2001.

VIZA, Floresta Maria Soeiro. Reflexões sobre a evolução do Serviço Social no Espírito Santo (década de 50). 1981. Dissertação (Mestrado em Serviço Social) - Pontifícia Universidade Católica do Rio de Janeiro, Rio de Janeiro. 1981.

VIZA, Floresta Maria Soeiro. Quarenta ano de serviço social no Espírito Santo - 1950/1990. Revista de Cultura da UFES, Vitória, ano XVI, n. 44/45. 1990.

XAVIER, Gabriella de Sousa; MASCARENHAS, Raquel Mota. A Emergência do Serviço Social no Espírito Santo: a "questão social" em foco. Trabalho de Conclusão de Curso (Graduação de Serviço Social) - Universidade Federal do Espírito Santo, Vitória. 2009. 